\title{
Dissolved helium and TDS in groundwater from Bhavnagar in Gujarat: Unrelated to seismic events between August 2000 and January 2001
}

\author{
S K Gupta* and R D Deshrande \\ Physical Research Laboratory, P.O. Box 4218, Navrangpura, Ahmedabad 380 009, India
}

\begin{abstract}
Temporal variations have been observed in both dissolved helium and TDS in the form of increase in basaltic and decrease in alluvial aquifers. The increase in basaltic aquifers has been explained by enhanced pumping of old groundwater with relatively higher concentration of dissolved helium and salt, whereas the decrease in alluvial aquifers has been explained by dilution from the post monsoon groundwater recharge. Therefore, the observed temporal variations cannot be ascribed to the contemporary enhanced seismic activity in this region since August-September 2000.
\end{abstract}

\section{Introduction}

Helium- 4 is radiogenic, produced in decay of uranium and thorium series nuclides in soils and rock grains within the Earth. The gas is steadily released from grains by their etching, dissolution, fracturing and alpha recoil during weathering and then exhaled into the atmosphere by diffusion and temperature variations. The Earth's atmosphere has a small concentration of helium since it quickly escapes to the outer space. Since the production of both ${ }^{4} \mathrm{He}$ and radon occurs within the Earth, their concentrations show a gradient decreasing towards the ground-atmosphere interface. Before escaping to the atmosphere through fractures, these gases are intercepted by the omnipresent groundwater zone. Since the diffusivity of helium in water is small $\left(7.78 \times 10^{-5} \mathrm{~cm}^{2} \mathrm{~s}^{-1}\right.$ at $25^{\circ} \mathrm{C}$; CRC Handbook, 80th edition, 1999-2000), it generally follows groundwater flow.

While a part of the radiogenic helium is released to the atmosphere the remaining fraction continues to accumulate in grains. Episodes of rock dilation and fracturing may occasionally release this fraction. On such occasions, and for a short period of time, this fraction may dominate over steady-state release. Creation of micro-fractures due to slow build-up of strain resulting in escape of radiogenic helium and radon provides the basis of geochemical methods of earthquake prediction (Barsukov et al 1985a; Reimer 1985; Virk et al 2001). Tremors of significant magnitude can create new fractures in the crust and also unlock some that may already exist. Earthquakes can thus facilitate escape of helium through fractures and suddenly increase its concentration in the overlying groundwater zone. The sensitivity range of the gaseous components of groundwater including helium, radon, carbon dioxide and hydrogen sulphide has been estimated to be $300-500 \mathrm{~km}$ or more (Varhall et al 1985; Barsukov et al 1985b). On the basis of Tashkent precursor study during 1974-1980 an empirical formula $(\log R T=0.63 \mathrm{M} \pm 0.15)$ relating time $T$ to magnitude $M$ and epicentral distance $R$ had been put forward (Sultankhodzhayev et al 1980). Observations in helium content of Yavros flowing well waters in Dushanbe study area during 1977-79 have been useful in revealing that both precursor time and anomaly amplitude increased with magnitude of the following seismic event. The anomaly duration and amplitude decreased with epicentral distance. But in many other areas it is still uncertain if the observed anomalies were truly earthquake related or induced by other environmental

Keywords. Groundwater; Helium; TDS; Bhavnagar; seismicity. 

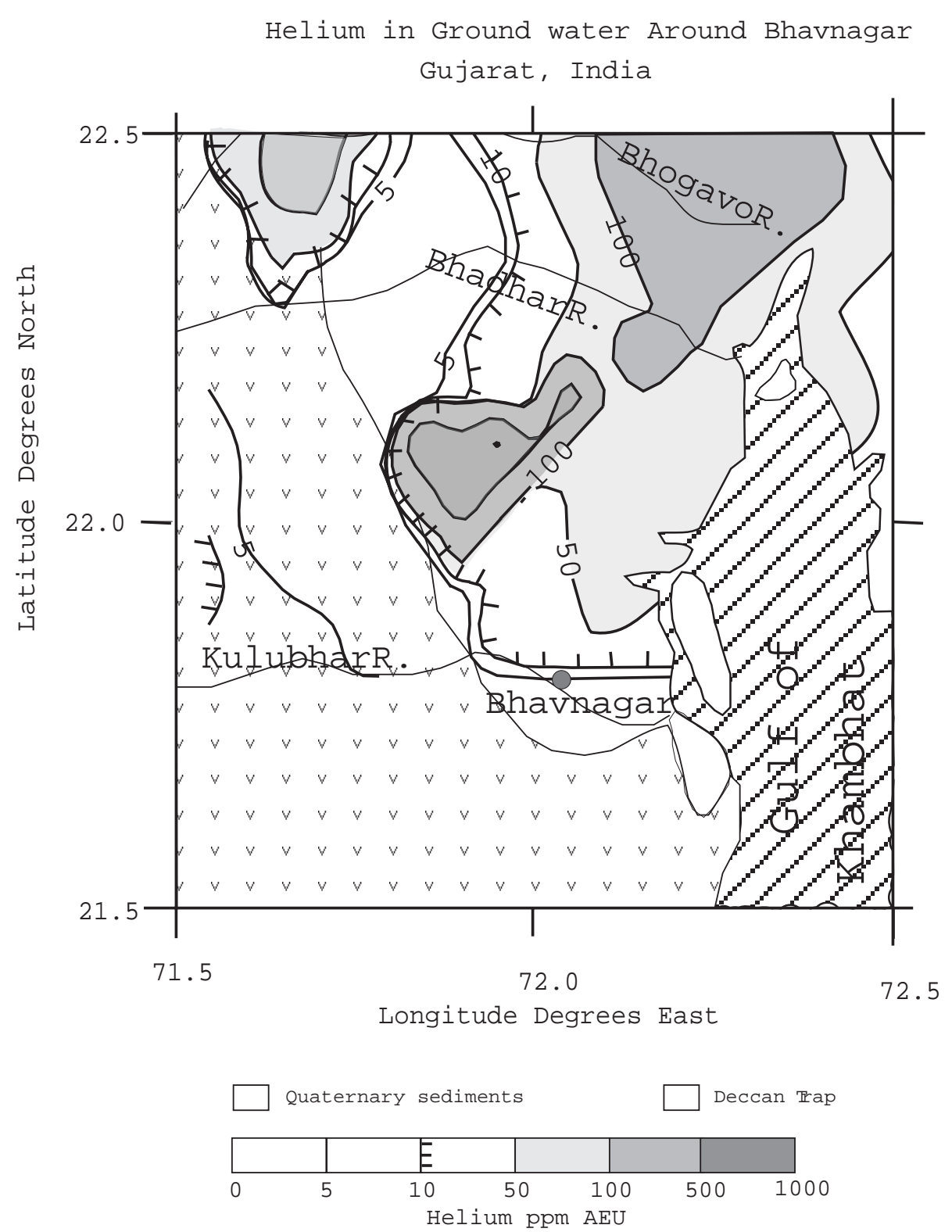

Figure 1. Contours of dissolved helium anomaly in groundwater in the region around Bhavnagar in March 1998, i.e., during a quiet seismic period.

variables such as weather and groundwater pumping (King 1985).

During the last two decades, Bhavnagar city $\left(21.86^{\circ} \mathrm{N} ; 72.04^{\circ} \mathrm{E}\right)$ in western India has intermittently experienced earthquakes of magnitude $>3$ (Srivastava and Rao 1997). The city is located on the southern tip of Saurashtra, which is bound by the extension of Narmada geofracture in the south and western Cambay Basin fault in the east. During 1979 and 1982, several earthquakes with epicentres in Bhavnagar, Chandod, Gulf of Khambhat, Rajpipla etc., located along the Narmada geofracture were experienced. A survey of dissolved helium in groundwater from parts of Cambay Basin during 1999 did indeed show significantly high con- centrations (figure 1) around Bhavnagar. During August-September, 2000 the frequency of small tremors around Bhavnagar increased significantly and presented an opportunity to test the earthquake induced helium release model in this part of the world.

Sixteen groundwater samples were collected from tubewells and hand pumps from different parts of the city (figure 2) on 16th and 17th September 2000. Some of the same stations were re-sampled on 22nd January 2001 after a long quiescence period for comparison. After the Bhuj earthquake of 26th January 2001, a repeat survey of these stations was conducted in March 2001. During the two repeat surveys, 


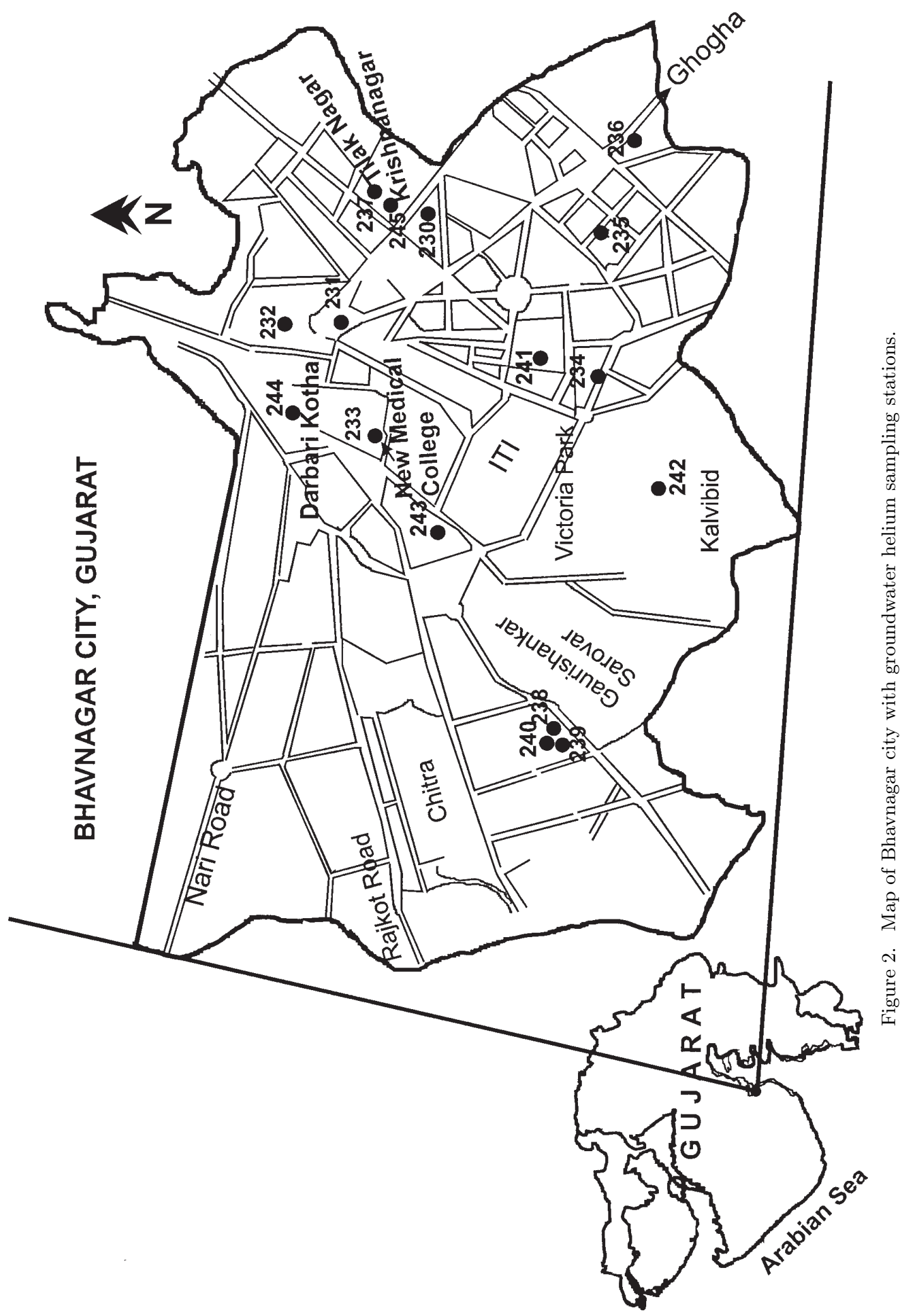


some of the original wells could not be resampled and had to be abandoned because of a decline in the water table and drying up of the wells. In such cases wells in the vicinity were sampled.

\section{Experimental}

Water samples for analyses of dissolved helium were collected in 3-mm thick, 1.2-litre capacity, soda-lime glass bottles using procedures standardised in our laboratory for these analyses and described earlier (Gupta et al 2002). Briefly, after complete purging of air by groundwater, the bottles were filled by the water samples up to the top and then water above a pre-determined level was quickly sucked off, keeping headspace for exsolving gases. The bottles were immediately sealed. The temperature, TDS and $\mathrm{pH}$ of groundwater samples were measured at the sampling stations using standard pre-calibrated probes.

The helium analyses were made on the equilibrated air from the headspace of the sampling bottles within a day using a helium sniffer probe (ALCATEL Model ASM 100 HDS) with a modified inlet port to enable quantitative helium analyses (see Gupta et al 2002). The measured helium concentrations are corrected for

- volume of headspace,

- water volume,

- volume of air drawn-in during analysis and

- loss during storage.

The equilibrated air helium concentrations can be converted to the groundwater helium concentrations using Henry's Law and the respective volumes of water and air /gas in the sampling bottles. Henry's constant is defined by $H=C_{g} / C_{w}=\{$ (concentration of helium in gas phase)/(concentration of helium dissolved in water) $\}$. Using $H=94.5$ (Fry et al 1995) at $25^{\circ} \mathrm{C}$, the concentration of dissolved helium in equilibrium with air containing $5.3 \mathrm{ppmv}$ helium is equivalent to $5.6 \times 10^{-2} \mathrm{ppmv}$. However, for the sake of convenience the dissolved helium concentrations are expressed here in terms of Air Equilibration Units (AEU), i.e., helium concentration in air that was in equilibrium with the water at one atmospheric pressure. Helium anomaly is defined as concentration above the atmospheric equilibration value of 5.3 ppmAEU). The reproducibility of sampling and measured helium concentration variation is $<5 \%$ (table 1).

\section{Results}

Twelve of the sixteen groundwater samples collected for dissolved helium survey in September
2000 (figure 2) showed helium concentrations more than the air equilibration value of 5.3 ppmAEU (table 2). The values ranged between 11 and $498.2 \mathrm{ppmAEU}$. The highest value was found in a groundwater sample from a $60-\mathrm{m}$ deep tubewell (\#233) followed by 179.5 ppmAEU from a 43-m deep tubewell (\#242). These values are much higher than those ( $\sim 20$ ppmAEU) found even in deeper tubewells (\#238, \#239, \#240) on the western outskirts of Bhavnagar. The groundwater temperatures ranged from $30^{\circ}-40^{\circ} \mathrm{C}$ and helium solubility changes due to these (Weiss 1971) cannot account for observed helium excesses.

Although a few studies (Datta et al 1980) had suggested that in alluvial aquifers, deeper groundwaters have higher helium concentration, subsequent measurements (Gupta and Deshpande 2003) and the present study indicate that in basaltic aquifers, this may not necessarily be the case. The present study, however, indicates that in the Bhavnagar city, high values of helium in groundwater are generally found in the basaltic aquifers and relatively low helium concentrations in the alluvial aquifer (see table 2). This observation is consistent with the understanding that interconnected pore space and high porosity in alluvial aquifers facilitate quick escape of helium from groundwater and the unconnected pore space and low porosity in basaltic aquifers limit the opportunity for groundwater helium to escape.

\section{Discussion}

The temporal variations of groundwater helium are plotted in figure 3. Some stations, particularly those with high levels of excess dissolved helium, showed a change by more than a factor of 2. From September 2000 to January 2001, except in case of stations \#233 \& \#244 located in the basaltic aquifers, helium concentrations have either not changed or decreased marginally. Between January and March 2001, five out of seven stations, again located in basaltic aquifers, showed increase in helium concentration. This increase was also accompanied by an increase in TDS (except Stn. \#238 \& \#239). It will also be noticed from figure 3 and table 2 that with respect to the data for September 2000, helium and TDS concentration changes in January and March 2001 have largely been in the same direction (increase/ decrease/ no change) for respective wells.

There also appears a certain pattern in the helium concentration and TDS between the three sets of sampling. It is seen that helium concentration changes (Sept. 2000 - March 2001; figure 4) at different stations are related to changes in (i) 


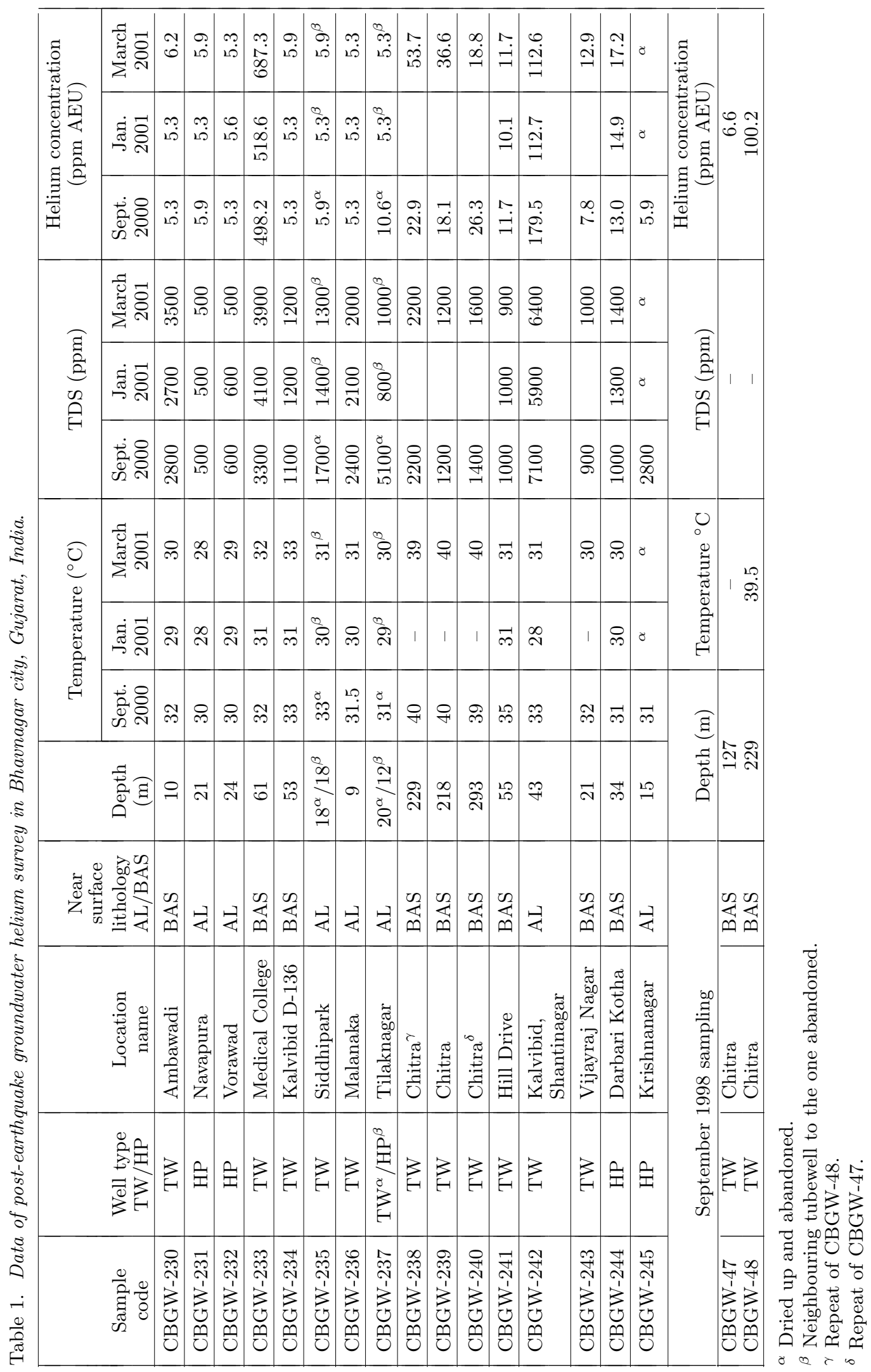


Table 2. Reproducibility of measured helium concentration in groundwater samples.

\begin{tabular}{lccc}
\hline Sample location & \multicolumn{2}{c}{ Helium concentration (ppmAEU) } & Variability $(\%)$ \\
\hline & Sample-1 & Sample-2 & \\
\hline Ranip & 6.17 & 6.20 & 1 \\
Bagodra & 339.7 & 339.7 & 0 \\
Roika & 24.3 & 24.8 & 2 \\
Tilaknagar & 5.3 & 5.3 & 0 \\
\hline
\end{tabular}

$\bar{\chi}$ In this case eight samples in different sampling bottles were collected at the same time and analysed over a period of two years to estimate loss of helium during storage in sampling bottles. This loss has been estimated to be $<0.15 \%$ per day.

TDS of groundwater and, (ii) the lithology of the aquifer.

It is recalled that the sampling dates correspond to three distinct seismic phases at Bhavnagar:

- September 2000 - during this period low magnitude $(<4.2)$ tremors were repeatedly experienced;

- January 2001 - a long quiescent phase preceded the sampling;

- March 2001 - quiescent period following a major (26th January 2001) earthquake (magnitude: 7.6, IMD; 7.9 USGS) with epicentre $>300 \mathrm{~km}$ in NE.

Based on the reports of seismically induced geochemical changes in groundwater and local hydro-geological observations, two possible models to explain the observed variations in helium and TDS are examined.

- Seismically induced release of helium and/or forced injection of deep groundwaters (in general with higher helium and TDS concentrations) to shallow aquifers.

- Pumping of deep groundwaters due to decline in water table leading to progressive increase in helium and TDS.

The first model is based on several reported cases of increase in helium and salts in groundwater in response to earthquakes (Barsukov et al 1985a; Reimer 1985; Virk et al 2001). Also, in case of the Bhuj earthquake, large-scale liquefaction and resultant oozing of groundwater accompanied by release of gases at many places over a large area extending from Rajasthan to south Gujarat has been reported (Rajendran et al 2001). It may be useful to note that at Narveri $\left(23.96^{\circ} \mathrm{N} ; 69.85^{\circ} \mathrm{E}\right)$; in the Great Rann of Kachchh an outflow of groundwater continued more than four months after the Bhuj earthquake (Gupta et al 2002). Air or gases bubbling through the freshly oozing water was observed at Narveri. Based on measurements of helium, radon, chloride, sulphate, sodium and temperature it was suggested that the outpouring water and escaping gases at Narveri had a deep confined source with a reservoir age in excess of $\sim 10^{4}$ years.

If seismically induced release of helium and/or forced injection of deeper groundwater were operative during the seismically active phase in September 2000, a decrease of helium concentration in the samples collected in January 2001 (quiescent phase) was expected. However, the decrease is observed only at three stations in alluvial terrain. In case of basaltic terrain, helium concentrations have either remained unchanged or have increased. This pattern of change in helium concentration has continued even in March 2001 (post Bhuj earthquake quiescent phase). This observed steady increase of helium concentration during quiescent phases in basaltic aquifers accompanied by no or marginal decrease in alluvial aquifers rules out the case of seismically induced injection of deep groundwater.

The second model is based on the observations that groundwater levels during successive sampling periods at Bhavnagar have steadily declined in basaltic terrain indicating pumping of progressively deeper (long resident) groundwater. As before, the deeper groundwater is expected to have higher concentrations of both helium and TDS due to longer residence in contact with aquifer material. This would explain the observed steady increase in both helium concentration and TDS in basaltic terrain. However, concurrent enhancement in helium and TDS concentrations in basaltic terrain and decrease or 'no change' in the alluvial terrain needs to be explained. One also needs to explain the nonlinearity of TDS and helium concentration variations (figure 4).

In aquifers comprising of secondary unconnected porosity in the form of fractures and fissures (e.g., the basaltic aquifers) groundwaters exhibit large spatial variability in dissolved constituents reflecting their largely local origin. This is clearly seen from table 2. The old groundwaters in such aquifers too will carry this spatial variability of dissolved constituents but with higher concentrations due to 


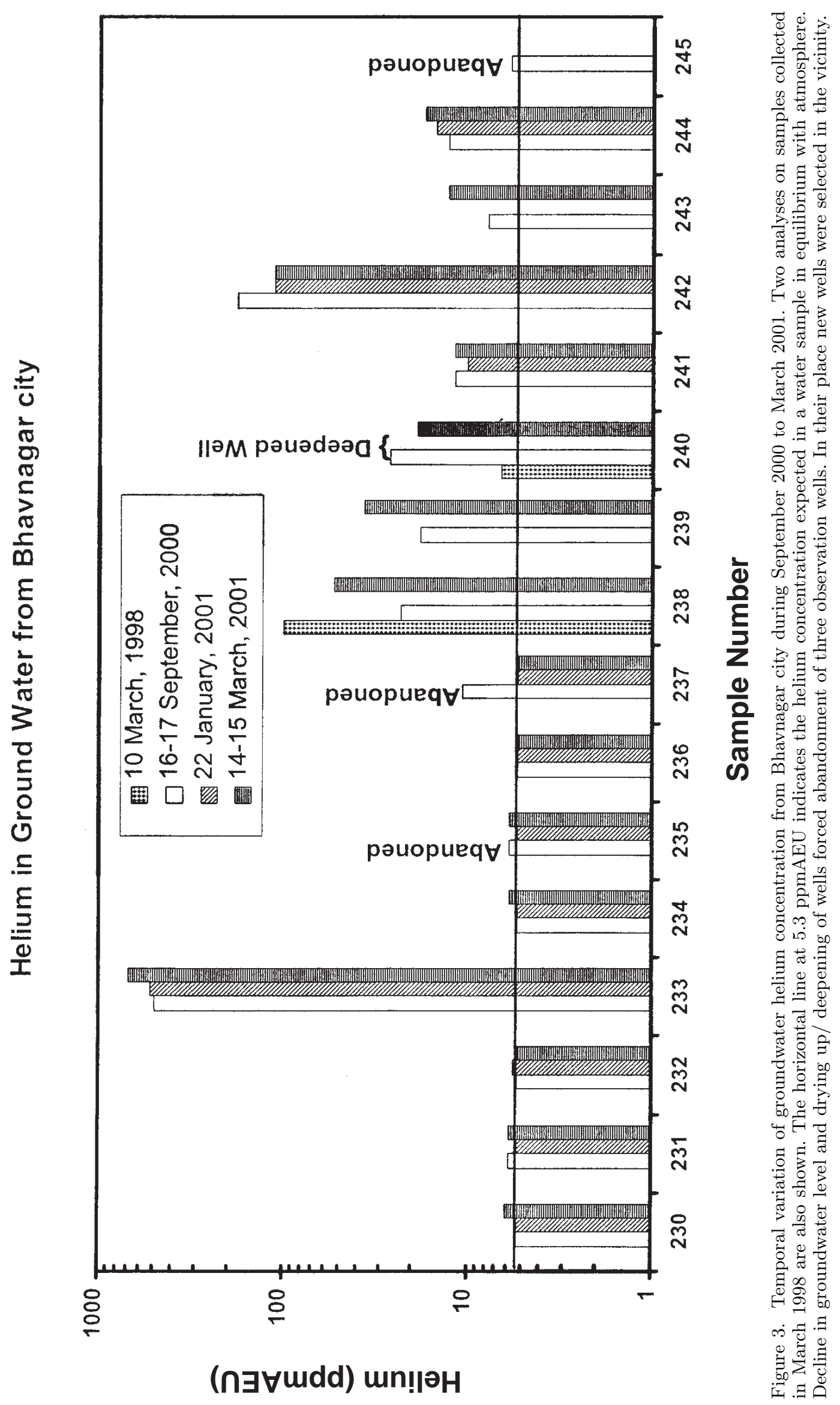




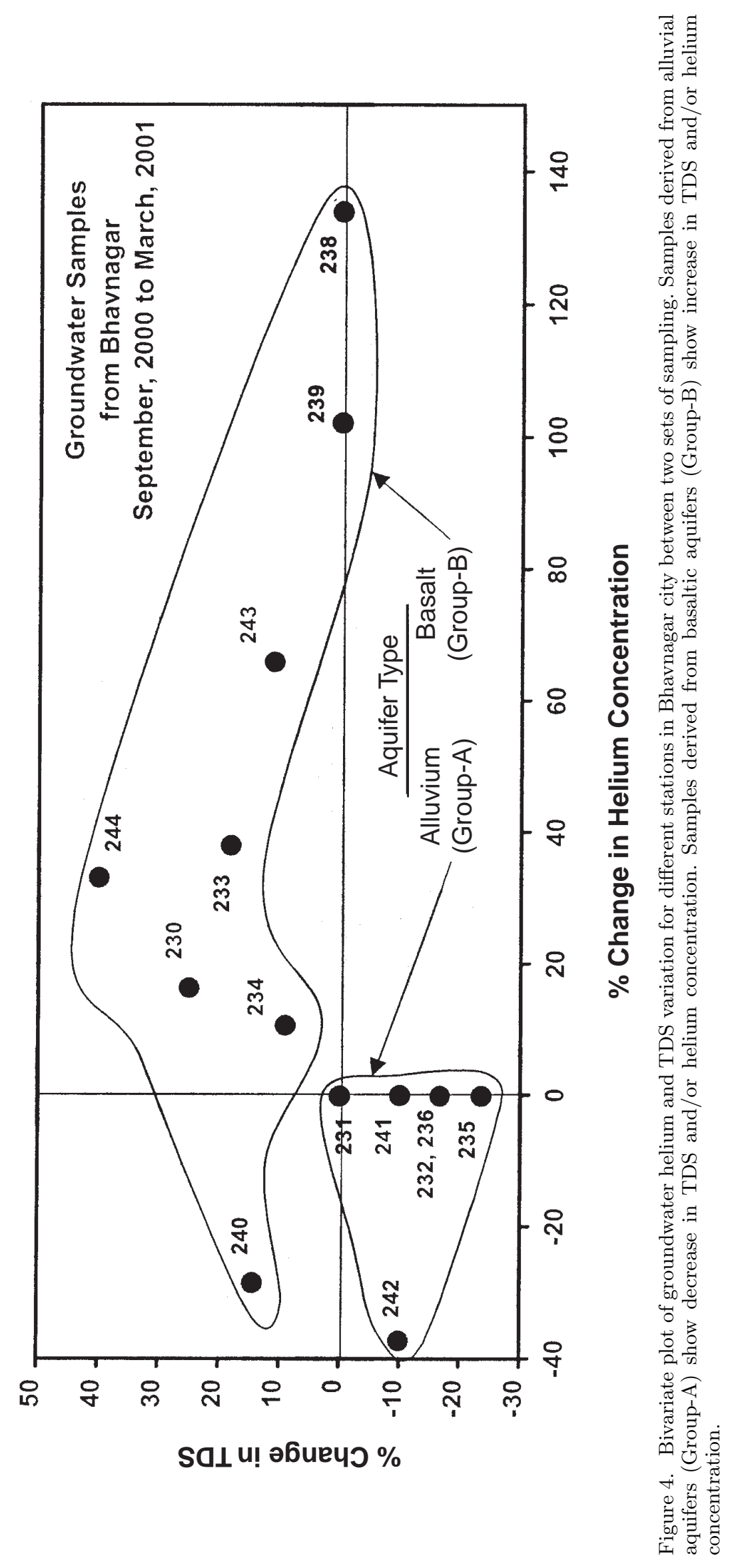


longer residence. The fractures and fissures quickly recharge these aquifers after the rain, but the amount is limited by the small availability of pore space. In post rainy season, excessive withdrawal of groundwater (as was indicated by decline in groundwater levels and drying up of some wells leading to their abandonment) results in pumping of old 'long resident' groundwater. This is in contrast to a relatively slow recharge that takes place during post monsoon period due to infiltration over a large area in regions of primary porosity such as alluvial aquifers. This recharge leads to slow but significant dilution of resident groundwater in alluvial aquifers in the post rainy season. Therefore, in a region having aquifers with both primary and secondary porosity correlation between variations of TDS and helium concentration in response to either mixing of old groundwater and/ or post monsoon recharge may exhibit considerable variation. The variability of this relationship is due to the inherent spatial variability in dissolved constituents in groundwater, the porosity and the permeability.

It is seen from figure 4 that stations falling in Group-A, showing decrease in TDS and little or no decrease in helium are drawn from aquifers in the alluvial terrain. These stations had relatively lower values (table 2) of both TDS and helium in September 2000. The observed reduction in January and March 2001, therefore, represent dilution with slow post monsoon recharge through the overlying soil. It may be noted that the post monsoon recharge will have a 'fixed' low (= 5.3 ppmAEU) concentration of helium and low (though not necessarily a 'fixed' value) TDS. In contrast, stations falling in Group-B, showing a significant increase (except \#240) in helium and moderate increase in TDS (except \#238 \& 239) are drawn from aquifers in the basaltic terrain. These stations, derived from the basaltic aquifers, had relatively high values of both TDS and helium in September 2000 (table 2). The observed increase in both TDS and helium in January and March 2001 represents pumping of relatively old groundwater with high but locally variable values of both TDS and helium due to the unconnected nature of secondary porosity.

\section{Summary and conclusions}

Temporal variations have been observed in both the concentration of dissolved helium and TDS of groundwaters at Bhavnagar following a period of locally enhanced seismic activity during AugustSeptember 2000. A significant aspect of the observed variation is the enhancement of helium and TDS concentrations in basaltic terrain and reduction in both parameters in alluvial terrain during the subsequent quiescent phases interrupted by a major Bhuj earthquake on 26th January 2001. Because of the large variability, it has not been possible to draw a quantitative relationship between the observed changes in TDS and helium concentration.

The observations have been explained by a model involving addition of deeper (old, long resident) groundwater in response to post-monsoon excessive pumping in the basaltic terrain and a concurrent dilution by slow post monsoon groundwater recharge in the alluvial terrain. The observed large variation is therefore due to the prevailing hydro-geological situation at Bhavnagar.

The steady increase of helium concentration in basaltic aquifers during quiescent phases, accompanied by little or marginal decrease in alluvial aquifers rules out the possibility that the observed variations were seismically induced.

\section{Acknowledgements}

The authors are thankful to Mr. G C Srivastava, Mr. P M Joshi, Mr. Y Sharma, Mr. S A Qureshi and Mr. D Dodia of GWRDC for identifying suitable sampling stations and fruitful discussions. We thank Prof. N Bhandari for critically reviewing the manuscript.

\section{References}

Barsukov V L, Varshall G M and Zamokina N S 1985a Recent results of hydrogeochemical studies for earthquake predictions in the USSR; $P A G E O P H$ 122(2-4) $143-156$

Barsukov V L, Serebrennikov V S, Belaev A A, Bakaldin Yu A and Arsenyeva R V 1985b Some experience in unravelling geochemical earthquake precursors; PAGEOPH 122(2-4) 157-163

Datta P S, Gupta S K, Jayasurya A, Nijampurkar V N, Sharma P and Plusnin M I 1980 A survey of helium in groundwater in parts of Sabarmati basin in Gujarat state and in Jaisalmer district, Rajasthan; Hydrological Sciences- Bulletin 25(2) 183-193

Fry V A, Istok J D, Semprini L, O'Reilly L T and Buscheck T E 1995 Retardation of dissolved oxygen due to a trapped gas phase in porous media; Groundwater 33(3) 391-398

Gupta S K, Bhandari N, Thakkar P S and Rengarajan R 2002 On the origin of the artesian groundwater and escaping gas at Narveri after the Bhuj earthquake in 2001; Curr. Sci. 82(4) 463-468

Gupta S K and Deshpande R D 2003 Origin of groundwater helium and temperature anomalies in the Cambay region of Gujarat, India; Chem. Geol. (in press)

King Chi-Yu 1985 Earthquake hydrology and chemistry; PAGEOPH 122(2-4) 141-142 
Rajendran K, Rajendran C P, Thakkar M and Tuttle M P 2001 The 2001 Kutch (Bhuj) earthquake: coseismic surface features and their significance; Curr. Sci. 80(11) $1397-1405$

Rao G V, Reddy G K, Rao R U M and Gopalan K 1994 Extraordinary helium anomaly over surface rupture of September 1993 Killari earthquake, India; Curr. Sci. 66(12) 933-935

Reddy G K, Rao G V, Rao R U M and Gopalan K 1994 Surface rupture of Latur earthquake: The soil-gas helium signature; Mem. Geol. Soc. India 35 83-99

Reimer G M 1985 Prediction of central California earthquakes from soil-gas helium fluctuations; PAGEOPH 122(2-4) 369-375

Srivastava S and Rao D T 1997 Present status of seismicity of Gujarat; Vayumandal, 27 (1-2) 32-39
Sultankhodzhayev A N, Latipov S U, Zarikov $\mathrm{T}$ Z, Zigan F G 1980 Dependence of hydrogeoseismological anomalies on the energy and epicentral distance of earthquakes; Dokl. AN Uzb. SSR 5 57-59

Varshall G M, Sobolev G A, Barsukov V L, Kohsov A V, Kostin B I, Kudinova T F, Stakheyev Yu I and Tretyakova S P 1985 Separation of volatile components from rocks under mechanical loading as the source of hydrogeochemical anomalies preceding earthquakes; PAGEOPH 122(2-4) 463-477

Virk H S, Walia V and Kumar N 2001 Helium/Radon precursory anomalies of Chamoli earthquake, Garhwal Himalaya, India; Journal of Geodynamics 31 201210

Weiss R F 1971 Solubility of helium and neon in seawater; Journal of Chemical Engineering Data 167 235-241 